http://jmscr.igmpublication.org/home/ ISSN (e)-2347-176x ISSN (p) 2455-0450

crossref DOI: https://dx.doi.org/10.18535/jmscr/v9i11.13

Journal Of Medical Science And Clinical Research

IGM Publication

An Official Publication of IGM Publication

\title{
Prevalence, Risk Factors Identification \& Parent's Concerness of the Consequences of Childhood Overweight \& Obesity in an Urban Area of Dhaka, Bangladesh
}

\author{
Authors \\ Gulshan Akhtar ${ }^{*}$, Afroza Khanam², Mohammad Abdur Rahman ${ }^{3}$ \\ ${ }^{1}$ Associate Professor, Department of Pediatrics, Green Life Medical College, Dhaka \\ ${ }^{2}$ Associate Professor, Department of Otolaryngology, Green Life Medical College, Dhaka \\ ${ }^{3}$ Assistant Professor, Department of Cardiology, Shaheed Sahrowardy Medical College, Dhaka \\ *Corresponding Author \\ Dr Gulshan Akhtar
}

Associate Professor, Department of Pediatrics, Green Life Medical College, Dhaka

\begin{abstract}
Background: Once considered a high income country problem, overweight and obesity are now on the rise in low and middle income countries, particularly in urban settings. In Bangladesh, beside under nutrition over nutrition is an emerging health problem increasing steadily particularly among affluent society.

Methodology: This cross sectional study was conducted among 220 school going children aged 6 to 15 years during one-year period from February 2019 to January 2020. Children who had history of any chronic illness or were on drugs that may lead to weight gain were not included in this study. A selfadministrative questionnaire was used to collect data. Health professionals took measurements of the participants' weight and height. Anthro Plus software from the World Health Organization was used to convert anthropometric data into a body mass index for age with a z-score to determine overweight and obesity. Microsoft Excel was used to enter data, which was then uploaded to SPSS version 22 for additional analysis.

Results: A simple random sample procedure was used to pick 220 school aged and adolescents between 6-15 years old for this study, with a response rate of $94.74 \%$. The respondents' average age was 13 years, with a standard deviation of \pm 1.41 . Overweight and obesity were found to be prevalent in $14 \%$ of the study population. Male children were more overweight and obese than female children. Our data suggest that, children who participated in more physical activities, such as playing typical outdoor games, were less likely to be overweight or obese, and thatadolescent group, prolonged sedentary duration and unhealthy eating behavior was linked to overweight and obesity among study population.

Conclusion: Prevalence of pediatric overweight and obesity is in increasing trend among Bangladeshi school aged children and adolescent due to a lack of adequate physical activity, high level of sedentary behavior and increased consumption of junk foods. Due to future burden of this problem various preventive strategies to combat childhood overweight and obesity need to be adopted and implemented besides creating awareness among children and their families.
\end{abstract}




\section{Introduction}

With about one-quarter of the global population, South Asia is the most populous and the most densely populated region in the world. All the eight countries that make up this region experience high rates of poverty, food insecurity and malnutrition, with child malnutrition being one of the most persistent public health challenges across the region. ${ }^{1,2}$ While the bulk of the research and literature dedicated to child malnutrition focuses on under nutrition, the other end of malnutrition, i.e. over nutrition (overweight and obesity) has received far less attention especially among children., ${ }^{3,4}$ Concomitant with the decreasing but still high prevalence of undernourished children, the prevalence of childhood overweight (OW) and obesity (OB) is also becoming a growing concern in the lowmiddle-income countries (LMICs) like in South Asia. Steady economic prosperity, greater availability of food and high caloric consumption, and improving living standards are the likely contributors to the demographic and nutritional transition marked by the coexistence of over and under nutrition- a nutritional phenomenon known as dual burden of malnutrition (DBM). ${ }^{5,6,7}$

The worldwide prevalence of OW/OB nearly tripled between 1975 and 2016. The prevalence of OW and OB among children and adolescent (5-18 years) has risen dramatically from just $4 \%$ in 1975 to over $18 \%$ in 2016 (19\% boys and $18 \%$ girls were $\mathrm{OW})$. It is estimated now that most of the world's population live in countries where OW and OB kills more people than underweight. ${ }^{8}$ In 2019, an estimated 38.2 million children under 5 years were OW/OB. Globally there are more people who are obese than underweight, this occurs in every region except parts of sub Saharan Africa and Asia. ${ }^{8}$ Childhood OW and $\mathrm{OB}$ is a serious problem in USA. According to National Health and Nutrition Examination Survey (NHNES) 2017-2018, OB prevalence was $13.4 \%$ among 2-5 years, $20.3 \%$ among 6-11 years and $21.2 \%$ among 12-19 years old children. ${ }^{11,12}$ According to a recent report, out of 43 million OB children worldwide in 2010, approximately $18 \%$ were from developing countries, half of which (18 million) were reported to be living in Asia despite the huge burden of undernutrition. ${ }^{13}$

In Bangladesh, several studies regarding prevalence of pediatric OW/OB has been conducted in the preceding years but a few included countrywide surveys. In a countrywide epidemiological study conducted among 6 to 15 years old children on 2014 revealed $9.5 \%$ children were OW and $3.5 \%$ children were OB particularly in urban setting in Bangladesh. ${ }^{14}$ Another large group study conducted among 5000 children (2-10 years) residing in Dhaka city showed $7.6 \%$ children were obese (56.8\% boys and $43.2 \%$ girls). ${ }^{15}$ Another study conducted among 100 children in 2019, (5-16 years old) in urban setting revealed $23 \%$ children were OW and $77 \%$ were OB. ${ }^{16}$ Study conducted by Mohsin F et all, among 3-18 years old 468 children showed prevalence of OB was $17.9 \%$ (19.9\% male, $15.3 \%$ female) in the capital city, Dhaka. ${ }^{17}$

Overweight and obese children are usually identified as a part of routine medical care and the parents are often un aware that the child has excess weight. It is often necessary to begin by helping the family understand the importance of healthy weight for current and future health issues, especially because intervention requires considerable effort by child and family. ${ }^{18}$ Monitoring growth pattern of the child should be a mandatory part of each health care visit. As obesity is preventable, if abnormal weight gain is identified, evaluation of its cause and parental counseling regarding negative consequences of OW/OB and appropriate interventions will help the child remain healthy.

The fundamental cause of $\mathrm{OB}$ and $\mathrm{OW}$ is an energy imbalance between calorie consumed and calorie expended. ${ }^{8}$ Prenatal risk factors for development of OW/OB are: high pre conceptual weight, maternal gestational weight gain, large birth weight, maternal smoking and intra uterine growth restriction (IUGR). Post-natal factors include: OW/OB parents, feeding habit, lack of 
physical activity, prolonged sedentary habit, prolonged screen time, reduced duration of sleep, lack of parental knowledge regarding healthy feeding practices, family eating habits including some social and environmental factors. ${ }^{18}$ Childhood OW and OB can profoundly affect children's physical health, social and emotional wellbeing as well as self-esteem. Negative health consequences include insulin resistance, type II DM, dyslipidemia, hypertension (HTN), asthma, early puberty, obstructive sleep apnea (OSA), orthopedic complications, nonalcoholic steatohepatitis and many more. Negative psychological consequences include low selfesteem, poor body image, bullying, depression, and eating disorder. ${ }^{19}$

Eating pattern and eating behavior is another potential risk factor related to childhood OW/OB. Eating pattern is different in each family and is largely dependent on socioeconomic condition, preference for calorie rich foods and individual concern about maintaining healthy weight. Children watch and learn from adults and their elder sibs. Unless the family has healthy eating behavior and are physically active the child in the family cannot be expected to do so. So, in our present study we observed whether the either or both parent was cautious regarding their child being OW/OB.

The purpose of our current study was to see the prevalence, identify the possible risk factors and observe the concerns of parents of overweight/obese children regarding their child's current health status. As a family who eats healthy and is physically active and concerned about maintaining healthy weight will definitely outgrow healthy children.

\section{Methods}

\section{Conceptualization of the study}

The objective of our current study was to see the prevalence of childhood OW and OB, identify its possible risk factors and observe parent's awareness regarding their child's current weight. We observed sociodemographic factors of study population and respondent parents (age, sex, anthropometric measurement, BMI, birth weight, parental education level and occupation, monthly family income). These variables were chosen for the analysis based on their demonstrated link with nutritional and overall health status of individuals. The child's nutritional status is a multifaceted outcome that results from interaction among a wide range of proximal and distal factors occurring in the environment within which a child lives. For instance, the nutritional status is greatly influenced by the dietary environment of the household which itself is influenced by the financial and cultural factors. Mother's knowledge and education regarding child caring also play vital roles in child health outcomes. ${ }^{20}$ (REF: Ghose Bishwajit \& Sanni Yaya. Overweight and Obesity in under 5 children in south Asia. Child and Adolescent Obesity 2020; 3 (1): 105-121).

Data Collection: A systematic questionnaire was used to obtain data from the study population. The questionnaire used in our study was modified and prepared from Healthy Eating and Physical Activity survey, which includes: School Physical Activity and Nutrition Survey 2010 (SPANS-10), Child Feeding Questionnaire (CFQ), The Family Eating and Activity Habit Questionnaire-Revised (FEAQ-R) and The Dieting Belief Scale (DBS). Modification was done according to context of our country. 220 parents of the enrolled study sample were interviewed during the study. To preserve consistency, the questionnaire was written in English, then translated into Bangla, the local language, and then back to English. A one-day training session was held for 5 data collectors and 2 supervisors to raise awareness of data gathering, protocols, and data collection techniques. Data on sociodemographic factors, feeding habits and frequencies (carbohydrate, junk foods, confectionary items and sweetened drinks), duration of physical activity and sedentary behavior were collected using a structured questionnaire. To guarantee questioner consistency and quality, a pretest was conducted with $5 \%$ of the total sample size, which was 
equivalent to the study environment. The lead investigator and supervisors were in charge of daily data follow-up and two Journal of Obesity checkups.

Study Place and Period: We conducted this cross-sectional study in seven schools in the Dhanmondi region of Dhaka, Bangladesh, from February 2019 to January 2020. We selected these schools based on three criteria: large numbers of students, reputation for better educational standard and availability of playgrounds in schools. Each of the seven schools were private and three of the seven schools was English medium.

Study Population: The age of the study populations were 6-15 years who were enrolled in grades $2-10$. The study population consisted of students who enrolled in the designated schools during the data collection period.

Inclusion and Exclusion Criteria: All students in grades 2 to 10 with ages ranging from 6 to 15years who were present during the data collection time were included in the study. While students belonging to the referred age group who had history of any chronic illness or were on medications that may lead to excess weight gain were excluded.

Sample Size: This cross-sectional study was conducted on a total of 220 participants.
Data Analysis: For subsequent analysis, clean coded data was imported into Microsoft Excel and exported to SPSS version 22. Sentences, graphs, tables, frequencies, percentages, and mean and standard deviation were used to describe descriptive statistical analysis. On a bivariable level, factors linked to being overweight were discovered, and variables with a $p$ value of 0.2 or less were incorporated into a multivariable analysis to compensate for potential confounders. The odds ratio was used to quantify the strength of the link and was presented with 95 percent confidence intervals; for overweight and obesity, a $\mathrm{p}$ value of 0.05 was considered statistically significant.

\section{Results}

A total of 220 participants participated with a response rate of $94.6 \%$. Among the respondent parents $140(64 \%)$ were mothers and $80(36 \%)$ were fathers. Most of the either parents completed study up to higher secondary. Occupation wise majority of the fathers 129 (58.7\%) were service holder and most of the mothers $182(83 \%)$ were housewife. Among the participants, majority (71\%) belonged to middle income family (monthly income $\geq 25,000-<50,000$ BDT). (Table 1)

Table 1: Sociodemographic characteristics of the respondent parents

\begin{tabular}{lcc}
\hline Characteristics & Frequency $(\mathbf{n}=\mathbf{2 2 0})$ & Percentage $\mathbf{( \% )}$ \\
\hline RESPONDENT PARENTS & & \\
GENDER & 80 & 36 \\
Father & 140 & 64 \\
Mother & 33 & 15 \\
FATHER'S EDUCATION & 110 & 50 \\
Secondary & 77 & 35 \\
Higher Secondary & 129 & 58.7 \\
Graduate & 91 & 41.3 \\
FATHER'S OCCUPATION & & 28 \\
Service Holder & 61 & 53 \\
Businessman & 117 & 19 \\
MOTHER'S EDUCATION & 42 & \\
Secondary & & 83 \\
Higher Secondary & 182 & 17 \\
Graduate & 38 & 71 \\
MOTHER'S OCCUPATION & & 29 \\
Housewife & 156 & \\
Service Holder & 64 & \\
MONTHLY FAMILY INCOME & & \\
$\geq 25,000-<50,000$ BDT & & \\
$\geq 50,000$ BDT & &
\end{tabular}


Out of 220 participants, majority children were adolescents $(71 \%)$ followed by (29\%) belonging to 6-10 years age. Most of the participants 128 (58\%) were male and $92(42 \%)$ were female. Children's birth weight ranges from $<2.5 \mathrm{~kg}$ to $>4$ $\mathrm{kg}$, where majority $183(83 \%)$ were in range of normal birth weight (2.5 to $3.9 \mathrm{~kg}$ ). $134(61 \%)$ children were overweight and $86(39 \%)$ were in obese category. (Table 2)

Table 2: Sociodemographic characteristics of the study population

\begin{tabular}{lcc} 
Characteristics & Frequency $(\mathbf{n = 2 2 0})$ & Percentage $\overline{(\%)}$ \\
\hline STUDY POPULATION CHARACTERISTICS & & \\
AGE & 64 & 29 \\
$6-10$ years & 156 & 71 \\
$11-15$ years & 128 & 58 \\
SEX & 92 & 42 \\
Male & & 9.2 \\
Female & 20 & 83 \\
BIRTH WEIGHT & 183 & 7.8 \\
$<2.5 \mathrm{~kg}$ (low birth weight) & 17 & 0 \\
$2.5-3.9$ kg (normal birth weight) & & 61 \\
$\geq 4 \mathrm{~kg} /$ more (large for gestational age) & 0 & 39 \\
BMI & 134 & \\
$5^{\text {th }}-<85^{\text {th }}$ centile (Normal) & 86 & \\
$\geq 85^{\text {th }}$ centile $-<95^{\text {th }}$ centile (overweight) & & \\
$\geq^{\text {th }}$ centile (obese) & &
\end{tabular}

Regarding dietary habits of the study participants, nearly half, $99(45.2 \%)$ and $96(43.7 \%)$ of participants were eating rice/noodles/pasta around 3-4 times/week and $\geq 5$ times/week respectively. $128(58.3 \%)$ were taking high calorie snacks $\geq 5$ times/week and $83(37.6 \%)$ were taking high calorie snacks 3-4 times/week. 114 (52\%) were taking confectionary items and 143(65.2\%) were drinking soft drinks $\geq 5$ times/week. (Table 3 )

Table 3: Dietary characteristics of study population $(n=220)$

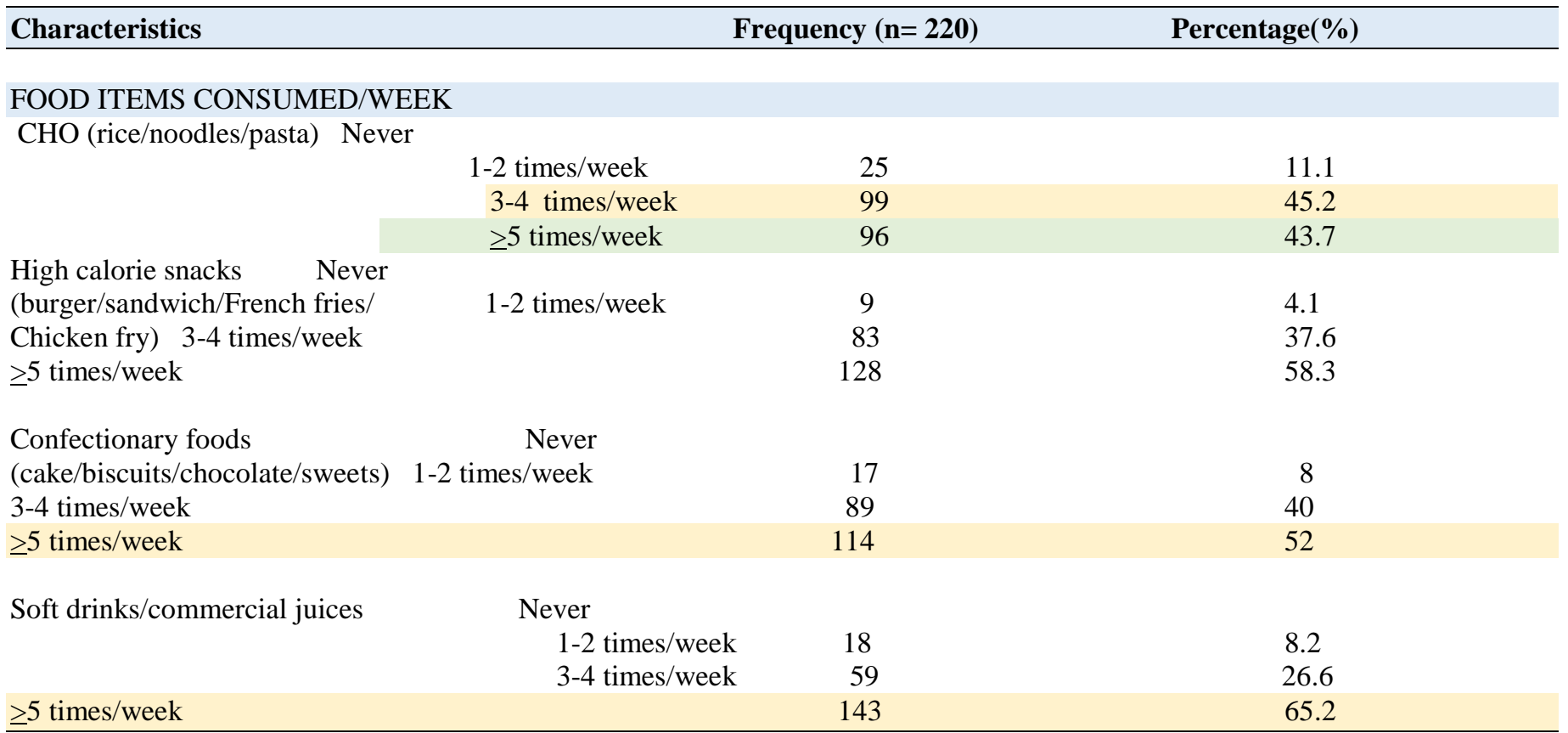

Low junk food consumption ( $<2$ times/week)

High junk food consumption ( $\geq 2$ times/week) 
Types of sedentary behavior such as watching TV, using computer, mobile/Tabs, playing video games, chatting around was more commonly observed among study population. Nearly half, $110(49.5 \%)$ participants were watching TV for $>3$ hours/day. More than half $138(62.5 \%)$ of the participants were using computer and playing video games on mobile for about 1-3 hours/day. Details were shown in table 4.

Table 4: Sedentary characteristics of study population on both week days and weekends $(n=220)$

Characteristics

\begin{tabular}{llllc} 
Sedentary Behavior & Never & $<1$ hour & $1-3$ hours & $>3$ hours \\
& $\mathrm{n}(\%)$ & $\mathrm{n}(\%)$ & $\mathrm{n}(\%)$ & $\mathrm{n}(\%)$ \\
Watching TV & $(0)$ & $22(10)$ & $88(40.2)$ & $110(49.8)$ \\
Using computer/mobile & $(0)$ & $27(12.4)$ & $138(62.5)$ & $55(25.1)$ \\
Playing video games & $(0)$ & $7(3.3)$ & $75(33.9)$ & $138(62.8)$ \\
Reading (for pleasure) & $89(40.3)$ & $110(50)$ & $16(7.2)$ & $5(2.5)$ \\
Hobbies (doing crafts/painting) & $11(5)$ & $83(37.5)$ & $114(51.8)$ & $12(5.7)$ \\
Lego making/solving puzzle & $22(10)$ & $149(67.7)$ & $44(20.2)$ & $5(2.1)$ \\
Sitting around/gossiping/chatting & $14(6.5)$ & $44(20)$ & $107(48.6)$ & $55(24.9)$ \\
\hline
\end{tabular}

Sedentary Activity: $<2$ hours/day

High Sedentary Activity: $\geq 2$ hours/day

Regarding physical activity, more than half of the participants had little to none physical activities.

Around $30 \%$ participants were engaged with some sort of physical activities (table 5).

Table 5: Type and Frequency of Physical Activity by study population per week $(n=220)$

\begin{tabular}{|c|c|c|c|c|c|}
\hline Characteristics & $\begin{array}{l}\text { None } \\
\mathrm{n}(\%)\end{array}$ & $\begin{array}{l}1-2 \text { times/wk } \\
\mathrm{n}(\%)\end{array}$ & $\begin{array}{c}\text { 3-4 times/wk } \\
n(\%)\end{array}$ & $\begin{array}{l}\text { 5-6 times/wk } \\
\mathrm{n}(\%)\end{array}$ & $\begin{array}{l}\geq 7 / \mathrm{wk} \\
\mathrm{n}(\%)\end{array}$ \\
\hline Walking (as exercise) & $123(56)$ & $71(32.1)$ & $15(7)$ & $11(4.9)$ & $(0)$ \\
\hline Running & $106(48.3)$ & $82.5(37.5)$ & $22(10.2)$ & $6(3.3)$ & $4(2)$ \\
\hline Jogging & $80(36.4)$ & $60(27.2)$ & $37(16.8)$ & $25(11.5)$ & $18(8.1)$ \\
\hline Cycling & $90(41)$ & $86(39.1)$ & $27(12.3)$ & $17(7.6)$ & (0) \\
\hline Skipping & $130(59.5)$ & $67(30.5)$ & $16(7)$ & $7(3)$ & (0) \\
\hline Playing in playground & $75(34)$ & $88(40.2)$ & $33(15)$ & $17(7.6)$ & $7(3.2)$ \\
\hline Dancing & $66(30)$ & $122(55.5)$ & $27(12.3)$ & $5(2.2)$ & $(0)$ \\
\hline
\end{tabular}

Sedentary/Low Physical Activity ( $<3$ times/week). Active/ High Physical Activity ( $\geq 3$ times/week)

More than half 116 (53\%) parents were concerned about their child eating more than required, 110 $(50 \%)$ parents were concerned about thei child becoming over weight/obese and 106 (48\%) parents were concerned that the child should diet to maintain healthy weight. (Table 6)

Table 6: Frequency of parents concerned about their child's current weight $(n=220)$

\begin{tabular}{|c|c|c|c|}
\hline \multirow[b]{2}{*}{ Habit } & \multicolumn{3}{|c|}{ Response of Parents } \\
\hline & $\begin{array}{l}\text { A little concerned } \\
\mathrm{n}(\%)\end{array}$ & $\begin{array}{l}\text { Concerned } \\
\mathrm{n}(\%)\end{array}$ & $\begin{array}{l}\text { Very much concerned } \\
\mathrm{n}(\%)\end{array}$ \\
\hline $\begin{array}{l}\text { Concerned about the child } \\
\text { eating more than required }\end{array}$ & $64(29 \%)$ & $116(53 \%)$ & $40(18 \%)$ \\
\hline $\begin{array}{l}\text { Concerned about the child } \\
\text { becoming OW/OB }\end{array}$ & $70(32 \%)$ & $110(50 \%)$ & $40(18 \%)$ \\
\hline $\begin{array}{l}\text { Concerned about the child } \\
\text { should diet to maintain } \\
\text { healthy weight }\end{array}$ & $79(36 \%)$ & $106(48 \%)$ & $35(16 \%)$ \\
\hline
\end{tabular}


$14.1 \%$ participants who were within the age range of 11 to 15 years developed OWor OB. Most prevalence of OW/OB (21.4\%) were found in participants who belonged to rich families (monthly income $\geq 50,000$ BDT). 66 children were highly physically active so the percentage of OW/OB was low (4.6\%) among this group. Among 154 children with low physical activity level $24.3 \%$ developed OW/OB and $75.7 \%$ were normal weight. Also, among 176 children with high sedentary activity $18.6 \%$ developed OW/OB and $81.4 \%$ were normal weight. High junk food consumption was seen among 165 children of our study population and $22.5 \%$ among them were OW/OB. Whereas $9.5 \%$ out of 55 children who had low junk food consumption were OW/OB. (Table 7)

Table 7: Identified Socio demographic and Risk Factors related to childhood OW/OB among study population $(\mathrm{n}=220)$

\begin{tabular}{|l|c|c|c|}
\hline Characteristics & Cases & \multicolumn{2}{|c|}{ Overweight/obesity } \\
\hline & & Yes (\%) & No (\%) \\
\hline $6-10$ years & 64 & $15(24 \%)$ & $49(76 \%)$ \\
\hline $11-15$ years & 156 & $22(14.1 \%)$ & $134(85.9 \%)$ \\
\hline Male & 128 & $40(31.2 \%)$ & $88(68.8 \%)$ \\
\hline Female & 92 & $15(16 \%)$ & $77(84 \%)$ \\
\hline$<2.5 \mathrm{~kg}$ (low birth weight) & 20 & $2(8.3 \%)$ & $18(91.7 \%)$ \\
\hline $2.5-3.9 \mathrm{~kg}$ (normal birth weight) & 183 & $30(16.5 \%)$ & $153(83.5 \%)$ \\
\hline$\geq 4 \mathrm{~kg} /$ more (large for gestational age) & 17 & $1(8 \%)$ & $16(92 \%)$ \\
\hline$\geq 25,000-<50,000$ BDT & 157 & $11(11.1 \%)$ & $88(88.8 \%)$ \\
\hline$\geq 50,000$ BDT & 64 & $15(21.4 \%)$ & $55(78.5 \%)$ \\
\hline Secondary & 61 & $4(7 \%)$ & $57(93 \%)$ \\
\hline Higher secondary & 117 & $20(16.7 \%)$ & $97(83.3 \%)$ \\
\hline Graduate & 42 & $5(11.3 \%)$ & $37(88.7 \%)$ \\
\hline Low Junk Food Consumption & 55 & $5(9.5 \%)$ & $50(90.5 \%)$ \\
\hline High Junk Food Consumption & 165 & $37(22.5 \%)$ & $128(87.5 \%)$ \\
\hline Low Sedentary Activity & 44 & $5(11.2 \%)$ & $39(88.8 \%)$ \\
\hline High Sedentary Activity & 176 & $33(18.6 \%)$ & $143(81.4 \%)$ \\
\hline Low Physical Activity & 154 & $37(24.3 \%)$ & $117(75.7 \%)$ \\
\hline High Physical Activity & 66 & $3(4.6 \%)$ & $63(95.4 \%)$ \\
\hline
\end{tabular}

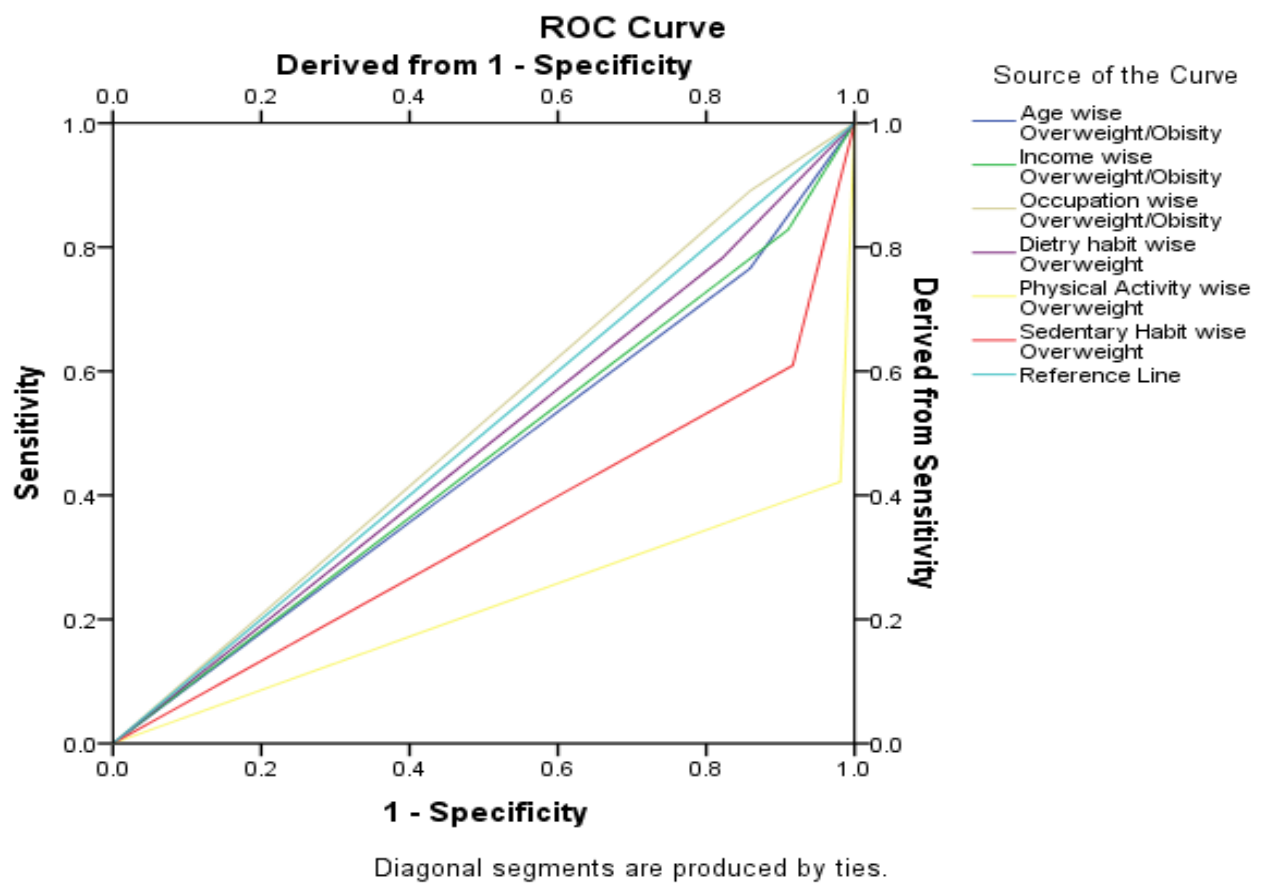

Figure 1: ROC Curve of Socio demography and Risk Factors related to childhood OW/OB among study population 
ROC curve \& Table 8 shows duration of physical activity and sedentary habit was highly significant $(\mathrm{p}<0.05)$ among the study population. Other variables were not significantly associated with OW/OB but were positively co-related.

Table 8: Area Under the Curve

\begin{tabular}{|c|c|c|c|c|c|}
\hline \multirow[b]{2}{*}{ Test Result Variable(s) } & \multirow[b]{2}{*}{ Area } & \multirow[b]{2}{*}{ Std. Error ${ }^{a}$} & \multirow[b]{2}{*}{ Asymptotic Sig. ${ }^{b}$} & \multicolumn{2}{|c|}{$\begin{array}{c}\text { Asymptotic } 95 \% \text { Confidence } \\
\text { Interval } \\
\end{array}$} \\
\hline & & & & Lower Bound & Upper Bound \\
\hline Age wise Overweight/Obesity & .453 & .044 & .277 & .367 & .539 \\
\hline Income wise Overweight/Obesity & .459 & .044 & .339 & .373 & .545 \\
\hline $\begin{array}{l}\text { Occupation } \\
\text { Overweight/Obesity }\end{array}$ & .516 & .043 & .713 & .433 & .599 \\
\hline Dietary habit wise Overweight & .480 & .043 & .648 & .395 & .565 \\
\hline $\begin{array}{lll}\text { Physical } & \text { Activity } & \text { wise } \\
\text { Overweight } & \end{array}$ & .221 & .040 & .000 & .142 & .299 \\
\hline $\begin{array}{l}\text { Sedentary } \\
\text { Overweight }\end{array}$ & .346 & .044 & .000 & .261 & .432 \\
\hline
\end{tabular}

The test result variable(s): Age wise Overweight/Obesity, Income wise Overweight/Obesity, Occupation wise Overweight/Obesity, Dietary habit wise Overweight, Physical Activity Wise Overweight, Sedentary Habit Wise Overweight has at least one tie between the positive actual state group and the negative actual state group. Statistics may be biased.

a. Under the nonparametric assumption

b. Null hypothesis: true area $=0.5$

Table 9 shows details coordinate of the ROC curve which shows the data of sensitivity and specificity of childhood OW/OB.

Table 9: Coordinates of the Curve

\begin{tabular}{|c|c|c|c|c|}
\hline \multicolumn{2}{|l|}{ Test Result Variable(s) } & $\begin{array}{c}\text { Positive if } \\
\text { Greater Than or } \\
\text { Equal To }{ }^{\mathrm{a}}\end{array}$ & Sensitivity & 1 - Specificity \\
\hline \multirow{2}{*}{\multicolumn{2}{|c|}{$\begin{array}{ll}\text { Age } & \text { wise } \\
\text { Overweight/Obesity } & \end{array}$}} & .0000 & 1.000 & 1.000 \\
\hline & & 1.5000 & .766 & .859 \\
\hline & & 3.0000 & .000 & .000 \\
\hline \multirow{3}{*}{$\begin{array}{l}\text { Income } \\
\text { Overweight/Obesity }\end{array}$} & wise & .0000 & 1.000 & 1.000 \\
\hline & & 1.5000 & .828 & .910 \\
\hline & & 3.0000 & .000 & .000 \\
\hline \multirow{3}{*}{$\begin{array}{l}\text { Occupation } \\
\text { Overweight/Obesity }\end{array}$} & wise & .0000 & 1.000 & 1.000 \\
\hline & & 1.5000 & .891 & .859 \\
\hline & & 3.0000 & .000 & .000 \\
\hline \multirow{3}{*}{$\begin{array}{l}\text { Dietary habit } \\
\text { Overweight }\end{array}$} & wise & .0000 & 1.000 & 1.000 \\
\hline & & 1.5000 & .781 & .821 \\
\hline & & 3.0000 & .000 & .000 \\
\hline \multirow{3}{*}{$\begin{array}{l}\text { Physical Activity } \\
\text { Overweight }\end{array}$} & wise & .0000 & 1.000 & 1.000 \\
\hline & & 1.5000 & .422 & .981 \\
\hline & & 3.0000 & .000 & .000 \\
\hline \multirow{3}{*}{$\begin{array}{l}\text { Sedentary } \\
\text { Overweight }\end{array}$} & wise & .0000 & 1.000 & 1.000 \\
\hline & & 1.5000 & 609 & .917 \\
\hline & & 3.0000 & .000 & .000 \\
\hline
\end{tabular}

The test result variable(s): Age wise Overweight/obesity, Income wise Overweight/ obesity, Occupation wise Overweight/obesity, Dietary habit wise Overweight, Physical Activity wise Overweight, Sedentary Habit wise
Overweight has at least one tie between the positive actual state group and the negative actual state group.

a. The smallest cutoff value is the minimum observed test value minus 1 , and the largest cutoff 
value is the maximum observed test value plus 1 . All the other cutoff values are the averages of two consecutive ordered observed test values.

\section{Discussion}

Adolescents social skills, physical attractiveness, emotional stability and quality of life are all influenced by nutrition at young age. Malnutrition has an impact on economic growth in terms of loss of productivity and increased illness burden. ${ }^{18}$ The goal of this study was to determine the prevalence of overweight/obesity in school-aged children and adolescents and the factors that contribute to it and observe parental concern regarding their child's current weight status. Males were found to be more likely than females to be overweight or obese with a ratio of 1.3:1 in the current study (Table 2). Because males are free to purchase more junk food from mobile carts of street sellers' junky items and cultural practices (like preference for male child in the family and giving him the more and best portion to eat) could be a possible cause of OW/ OB among male teenagers. Female teenagers on the other hand, are choosier in their dietary choices while keeping a star-like body image than male adolescents. Predominance of OW/OB among male children was found in other national and international studies by, Tania Bulbul et al, Monira Hossain et al, AshmitaKarki et al. ${ }^{12,14,19}$

We divided the total study population into two age groups, 6-10 years and 11-15 years. Prevalence of OW/OB was more among the adolescent group (Table 2). This finding was consistent with other studies by Tania Bulbul et al, Monira Hossain et al and Sholeh Rahman et al. ${ }^{12,14,21}$ However, study by AshmitaKarkiet al showed prevalence of OW/OB more among 6-9 years old children. ${ }^{19}$

Parental level of education in our study shows nearly half of the either parents completed higher secondary education (Table 1). We observed this variable as more educated parents are thought to have better knowledge regarding their child's nutrition, importance of maintaining healthy weight and physical activity and knows the negative consequences of childhood OW/OB. Significant association between parental education level and development of childhood OW/OB was seen in study by Rahman SMM et al and Ashmita Karki et al. ${ }^{13,19}$ In families where mother is the primary care giver, educated mothers were involved in professional jobs, so they had less time to monitor child's eating pattern, physical activity and duration of sedentary habit, these in turn increases BMI of their children. ${ }^{22}$ However, studies by Monira Hossain et al found no significant association between parental high education status and child's BMI. ${ }^{14}$ On the contrary, Sinead Brophy et al in their study observed, higher parental academic qualifications are associated with lower childhood obesity levels (Odds of OB: 0.63, 95\%CI: 0.52-0.77) if primary care giver leaves school after age 16 . They also stated, education level of the primary care giver is an important modifiable factor which can be targeted to address rising OB level in children. ${ }^{23}$

Majority of the fathers were service holder $(58.7 \%)$ and mothers were house wife $(83 \%)$ in our study. (Table 1). No significant association was seen between parental profession and child's BMI. Similar result was seen in study by Monira Hossain et al. ${ }^{14}$ On the contrary, children of mothers in a professional field had a greater likelihood of being OW/OB (95\% CI: 1.024.05). ${ }^{19}$

Table 1 shows average monthly income was $\geq 25$, $000-<50,000$ BDT in $45 \%$ of respondent parents followed by $31 \%$ had monthly income of $\geq 50,000$ BDT. Among 70 respondent high income families, $21.4 \%$ children and among 99 respondent middle income families, $11.1 \%$ children developed OW/OB. (Table 7) Monira Hossain et al and Sinead Brophy et al found no significant association between economic status of the family and development of OW/OB in their children. ${ }^{14,23}$ Whereas, Rahman SMM et al, Ashmita Karki et al and Faisal Muhammad et al in their study showed significant association of higher family income with increased child's BMI. $^{13,}$ 19, 24 Families with higher income can 
afford to expend more on food and regularly consume junk foods. ${ }^{13}$

Table 2 shows majority of study population (83\%) had normal weight at birth $(2.5-3.9 \mathrm{~kg})$, followed by low birth weight among $9.2 \%$ and macrosomia in $7.8 \%$. Weight status of the study group at birth had no association with development of OW/OB in later life in our study. This finding was similar to study result by AshmitaKarki et al which showed large birth weight was not significantly associated with OW/OB among primary school children in urban Nepal. ${ }^{19}$ Study by Eid EE and Stettler $\mathrm{N}$ et al showed higher birth weight and rapid growth in the $1^{\text {st }}$ few months of life are risk factors for overweight in both children and adults. $^{25,26}$

Dietary habit of our study population was categorized into low junk food consumption $(<2$ times/week) and high junk food consumption $(\geq 2$ times/week) and showed increased prevalence of OW/OB among high junk food consumption group. (Table 3, Table 7) Among 165 children with high junk food consumption habit, $22.5 \%$ developed OW/OB whereas only $9.5 \%$ children with history of low junk food consumption out of 55 cases developed OW/OB. (Table 7) This finding was consistent with other previous studies by Rahman SMM et al, Monira Hossain et al and Sinead Brophy et al. ${ }^{13,14,23}$ Sinead Brophy et al in their study revealed that children with higher BMI were weaned from breast milk before 3 months of age, had fewer portions of fruits intake/day and skipped breakfast regularly than non-obese children. $^{23}$

Table 4 shows type and duration of sedentary activity among study population on both week days and weekends and accordingly they were categorized into sedentary activity ( $<2$ hours/day) and high sedentary activity ( $\geq 2$ hours/day). Commonly observed sedentary behavior which was spent for > 3 hours/day were, use of electronic media (mobile, playing video games, using computer) in $62.8 \%$, watching TV in $49.8 \%$ and passing leisure time by gossiping or sitting around in $24.9 \%$. Among 176 high sedentary active children $18.6 \%$ developed OW/OB and $11.2 \%$ out of 44 low sedentary active children developed OW/OB. (Table 7). So the trend of OW/OB was high among children who were more sedentary in our study. Rahman SMM et al found energy expenditure and physical activity level were significantly lower among obese children. ${ }^{13}$ Monira Hossain et al in her study found watching $\mathrm{TV}>3$ hours/day had 4.4 times increased risk to develop obesity in children. ${ }^{14}$ AshmitaKarki et al in their study showed, children who exceeded the recommended screen time of less than or equal to 2 hours/day on weekends were 3 times more likely to be OW/OB than those who met the recommendation. $(\mathrm{a} \mathrm{OR}=3.0,95 \% \mathrm{CI}: 1.2-7.3)^{19}$

Table 5 shows type and frequency of physical activity by study population per week. Children who were physically active for $<3$ times/week were categorized as sedentary/low physical activity and children who were active $\geq 3$ times/week were considered as active/high physical activity. More than half of the participants had little to none physical activities.The common forms of physical activity performed by our study group at least 1-2 times/week were playing outdoor (40.2\%), cycling $(39.1 \%)$, running $(37.5 \%)$, walking as exercise (32\%), skipping (30.5\%) and jogging (27.2\%). Out of 154 children with low physical activity level $24.3 \%$ developed OW/OB and out of 66 children with high physical activity level only 4.6\% developed OW/OB. (Table 7) So, children who were involved in regular physical activity were less predispose to have increase BMI. Rahman SMM et al in his study revealed energy expenditure was significantly lower among OW/OB children. ${ }^{13}$ Whereas Monira Hossain et al and Ashmita Karki et al found no significant association between playing outdoor games and development of OW/OB. ${ }^{14,}{ }^{19}$ Reduced physical activities among children during home-stay could be linked to Dhaka's growing urbanization, which now has a population of over 15 million people. In response to the need for housing, the city is expanding in all directions, resulting of a 
reduction in open recreation spaces and, as a result, likely contributing to a change in children's and adults' physical activity patterns. However, because the healthy children in this study were involved in physical activities while living in the same location, the limited space issue was questioned. The area in which our current study was conducted have some playgrounds, walkable and cycling pathways, though the study group preferred to stay home instead of being physically active on weekends or their leisure time. One major contributing factor that make the parents limit their child's exposure to outdoor activities is that they usually do not feel safe for their children to allow them go outside unattended to be physically active.

Table 6 shows parental concern regarding their child's current weight status. It was observed that nearly half of the respondent parents were concerned that their child was eating more than required, they were gaining excess weight and the child should put restriction on their diet to maintain healthy weight $(53 \%, 50 \%$ and $48 \%$ respectively). Parental concern regarding their child's excess weight plays an important role in developing possible prevention strategies. ${ }^{27}$ If parents do not recognize childhood OW/OB as health risk, they are less likely to acknowledge this as a problem, making prevention and treatment difficult. ${ }^{28}$ Our study result shows that, the respondent parents were able to recognize that their child was overweight, had unhealthy eating behavior and the child should have a healthy diet as the parents consider excess weight of the child as a health risk. Study result by Etelson et al showed, although the parents seemed knowledgeable about healthy eating habits and the health risks of excess weight, more than half of the respondent parents in their study were unable to determine their own children's weight status. ${ }^{28}$

\section{Conclusion}

The current study showed that the prevalence of overweight and obesity among school aged children and adolescents is a high public health problem. Overweight and obesity among urban school students in Dhaka, Bangladesh, are linked to a number of risk factors, including insufficient physical activity in conjunction with high levels of sedentary behaviors and consumption of calorie rich foods. As obesity is preventable, some of our proposed preventive approaches include: promotion of exclusive breast feeding (EBF), appropriate complementary feeding practices, adequate physical activity, decrease screen time, proper parental knowledge of child's food and nutrition and routine child care visit to health care professionals for monitoring growth and early identification of abnormal weight gain. Besides these, combined effect of community leaders, politician \& health care professionals to provide safe walkable pathway and playground, control on media commercials on junk food advertisements, school meal programme, physically active hours during school time must be ensured. Failure to take appropriate actions may lead to serious public health consequences.

\section{Reference}

1. Akhtar S. 2016. Malnutrition in South Asia- a Critical Reappraisal. Crit Rev Food Science and Nutrition. 56(14): 2320-2330.

2. Anik Al, Rahman MM, Tareq MI et all. 2019. Double burden of Malnutrition at household level: A comparative study among Bangladesh, Nepal, Pakistan and Myanmar. PLos One. 14(8): e0221274.

3. Mastorci F, Vasalle C, Chatzianagnostou $\mathrm{K}$ et al. 2017. Undernutrition and Over nutrition burden for Diseases in developing countries: the role of oxidative stress biomarkers to assess disease risk and interventional strategies. Antioxidants. 6:2. Doi:10.3390/antiox6020041.

4. Ngaruiya C, Hayward A, Post L, et all. 2017. Obesity as a form of Malnutrition: Over nutrition on the Uganda Malnutrition agenda. Pan Afr Med J. 28.

5. Tanumihardjo SA, Anderson C, Kaufer Horwitz et al. 2007. Poverty, Obesity and 
Malnutrition: an international perspective recognizing the paradox. 2007. J Aca Nutri Diet. 107(11): 1966-1972.

6. Delisle H, Batal M. 2016. The Double Burden of Malnutrition associated with Poverty. Lancet. 387(10037): 2504-2505.

7. Peng W, Berry EM. 2018. Global Nutrition 1990-2015: A shrinking hungry and expanding fat world. PLos One. 13(3): e0194821.

8. NCD Risk Factor Collaboration (NCDRisC) 2017 Lancet 16; 390: 2627-2642.

9. Cheryl D, Fryar, M.S.P.H, Margaret D et all. Prevalence of Overweight, Obesity and Severe Obesity among children and Adolescents aged 2-19 years: US, 19631965 Through 2017-2018. Division of Health and Nutrition Examination Surveys.

10. De Onis M, Blossner M, Borghi E. Global prevalence and trends of overweight and obesity among preschool children. American Journal of Clinical Nutrition 2010; 92(5): 1257-1264.

11. Bhuiyan MU, Zaman S, Ahmeed T. Risk factors associated with overweight and obesity among urban school children and adolescent in Bangladesh: a case control study. BioMed Central Pediatrics 2013.

12. Tania Bulbul, Mozammel Haque. Prevalence of childhood Obesity and Overweight in Bangladesh: Findings from country wide epidemiological study. BMC Pediatrics 2014; 14: 86.

13. Rahman SMM, Kabir I, Bhuyan MAH et all. Prevalence and Determinants of Childhood Obesity in Dhaka City 2019; Bangladesh Medical Research Council Bulletin, 45(2): 68-80.

14. Monira Hossain, IsmotAraZannat, Suraiya Begum et all. Risk Factors for Overweight and Obesity among Children and Adolescents in BD: A Hospital based study. Bangladesh Journal of Child Health 2019; 43(1): 9-14.
15. Mohsin F, Tayeb S, Baki A, et al. Prevalence of Obesity among affluent school children in Dhaka. Mymensing Medical Journal, 2010; 19(4): 549-554.

16. Kleigman, Robert. Nelson textbook of pediatrics. Childhood Obesity. Edition 21. Philadelphia, PA: Elsevier, 2020.

17. Adekunle Sanyaulo, Chuku Okorie, Xiaohua Qi et all. Childhood and Adolescent Obesity in the United States: A Public Health Concern. Global Pediatric Health 2019; (6): 1-11.

18. J. R. Galler, F. Ramsey, G. Solimano, and W. E. Lowell, "the influence of early malnutrition on subsequent behavioral development: II. Classroom behavior," Journal of the American Academy of Child Psychiatry, vol. 22, no. 1, pp. 16-22,1983.

19. Ashmita Karki, Archana Shrestha, Narayan Subedi. Prevalence and associated factors of childhood Overweight/Obesity among primary school children in urban Nepal. BMC Public Health 2019. 19: 1055.

20. Ghose Bishwajit \& Sanni Yaya. Overweight and Obesity in under 5 children in south Asia. Child and Adolescent Obesity 2020; 3 (1): 105-121.

21. Sholeh Rahman, MdTouhidul Islam, Dewan S Alam. Obesity and Overweight in Bangladeshi children and adolescent: a scoping review. BMC Public Health 2014. $14: 70$.

22. Morrissey TW, Dunifon RE, Kalil A. Maternal Employment, Work Schedules and Children's BMI. Child Development 2011; 82(1): 66-81.

23. Sinead Brophy, Roxanne Cooksey, Micheal B Gravenor et al. Risk factors for childhood obesity at age 5: Analysis of the millennium cohort study. BMC Public Health 2009; 9: 467.

24. Faisal Muhammad, Mustafa Kabir Musa, ABM Alauddin Chowdhury et al. Risk factors of childhood Overweight and 
Obesity in young children and adolescents aged between 5-15 years in urban Bangladesh: A Scoping Review. Mal J Nutr 2016; 22 (3): 455-459.

25. Eid EE. Follow up study of physical growth of children who have had excessive weight gain in the $1^{\text {st }}$ six months of life. BMJ 1970; 2 (7): 4-6.

26. Stettler N, Zemel BS, Kumanyika S, Stallings VA. Infant weight gain and childhood overweight status in a multicenter cohort study. Pediatrics 2002; 109: 194-9.

27. Isabel Lin Tzou, Nain Feng Chu. Parental influence on childhood Obesity: A review. 2012; 4 (12A): 1464-1470.

28. Etelson D, Brand D A, Patrick P A et al. Childhood Obesity: Do parents recognize this health risk? Obesity Research 2003; 11: 1362-1368. 